\title{
BMJ Open HIV transmission knowledge among Rohingya refugee women in Bangladesh: a cross-sectional survey
}

\author{
Md Nuruzzaman Khan (D) , ${ }^{1}$ Md Mashiur Rahman, ${ }^{2}$ Md Mostafizur Rahman, ${ }^{3}$ \\ M Mofizul Islam (i) ${ }^{4}$
}

To cite: Khan MN, Rahman MM, Rahman MM, et al. HIV transmission knowledge among Rohingya refugee women in Bangladesh: a crosssectional survey. BMJ Open 2021;11:e047516. doi:10.1136/ bmjopen-2020-047516

- Prepublication history for this paper is available online. To view these files, please visit the journal online (http://dx.doi. org/10.1136/bmjopen-2020047516).

Received 01 December 2020 Accepted 17 September 2021

Check for updates

(c) Author(s) (or their employer(s)) 2021. Re-use permitted under CC BY-NC. No commercial re-use. See rights and permissions. Published by BMJ.

${ }^{1}$ Department of Population Science, Jatiya Kabi Kazi Nazrul Islam University, Mymensingh, Bangladesh

${ }^{2}$ Independent Researcher, Dhaka, Bangladesh

${ }^{3}$ Department of Population

Science and Human Resource Development, University of Rajshahi, Rajshahi, Bangladesh ${ }^{4}$ Department of Public Health, La Trobe University, Bundoora, Victoria, Australia

\section{Correspondence to} Md Nuruzzaman Khan; mdnuruzzaman.khan@uon. edu.au

\section{ABSTRACT}

Background and objective Increasing numbers of Rohingya refugees have been found to be infected with HIV since they arrived in Bangladesh after being ousted from Myanmar in 2017. This study aimed to examine the knowledge about HIV transmission among Rohingya refugee women and to identify factors that are associated with that knowledge.

Design A cross-sectional survey was conducted using a structured questionnaire that was based on the standard questionnaire of the Demographic and Health Survey programme.

Setting Rohingya settlements in the Kutupalong refugee camp at Ukhiya, Cox's Bazar, Bangladesh.

Participants Interviews were conducted with 508 women who had married or given birth in the 2 years before the survey was done.

Outcome measure The participants were asked to answer a set of questions to assess their knowledge about HIV transmission.

Results Around $70 \%$ of the women could not accurately answer four of the eight questions, and there were substantial misconceptions about the modes of HIV transmission. Knowledge regarding HIV transmission among participants increases in conjunction with the age at which they were first married. Women who were involved in work outside their households or those whose husbands were employed were more likely than others to demonstrate relatively good knowledge of transmission. Women who had received some formal education were 2.37 times likely to show relatively good knowledge of HIV transmission than those who had not received any education. Availability of healthcare facilities in the blocks where women resided is also associated with better knowledge. However, knowledge of HIV transmission among Rohingya women was significantly lower than among women in Bangladesh and Myanmar.

Conclusion Most Rohingya women have inadequate knowledge of HIV transmission. Targeted interventions are needed to provide HIV education and to assist with prevention and behavioural changes.

\section{INTRODUCTION}

The Rohingya people, a stateless minority group of Myanmar, are the most persecuted population in the world by the government of its own country. ${ }^{1}$ Historically, this persecution
Strengths and limitations of this study

Data were collected from a relatively large sample $(\mathrm{N}=508)$ and using a standard questionnaire.

- The study presents a comparative picture of the knowledge of HIV transmission among Rohingya, Bangladeshi and Myanmar women, which helps in recognising differences in their knowledge level and in developing appropriate programmes.

- Results were based on cross-sectional data, so a causal relationship could not be established.

- The scope of the study did not include validating knowledge about HIV transmission through asking additional questions.

- The regression model for knowledge of HIV transmission was adjusted for a limited set of confounding factors.

started in 1942 and flared up in 1945, immediately after Myanmar achieved independence from the UK. ${ }^{2}$ In 1977, the Rohingya people were identified as migrated labourers who had come from Bangladesh and India and were considered to be living in Myanmar illegally. A few years later, the government of Myanmar revoked the citizenship of the Rohingya people, following the enactment of a new citizenship law enacted in 1982, even though their roots had been in Rakhine State, in western Myanmar, since the eighth century. ${ }^{3}$ Consequently, the Rohingya people started fleeing to other countries in South and Southeast Asia, including Bangladesh, India, Malaysia and the Philippines. ${ }^{4}$ As the Rakhine State lies at the border of Bangladesh, it received the highest influx from this migration. In 1990, around 250000 Rohingya people had fled to Cox's Bazar in Bangladesh. In 2017, the total number increased to 1 million after another 723000 refugees joined the previous cohort. This latter group fled Myanmar after a military operation in response to the killing of Myanmar's 12 security personnel by the Arakan Rohingya Salvation Army (a non-state armed group). ${ }^{45}$ During 
the conflict in 2017, an estimated 7800-14000 Rohingya people were killed, ${ }^{6} 18000$ Rohingya women and girls were raped, ${ }^{78}$ and 116000 Rohingya people were beaten ${ }^{8}$ by the Myanmar military and local Buddhists. The operation drew criticism from the international community ${ }^{9}$ and eventually went to the International Court of Justice, which declared it to be genocide. ${ }^{10}$

In Bangladesh, the Rohingya refugees are located in two government-run refugee makeshifts positioned at Kutupalong and Nayapara in the Cox's Bazar district. ${ }^{11}$ These people reside in overcrowded temporary shelters and their access to healthcare is limited. ${ }^{112}$ The likelihood of exploitation and exposure to communicable diseases such as sexually transmitted infections (STIs) is high in such a situation. There are many reasons for this, including the higher occurrences of genderbased violence, ${ }^{13}$ inadequate knowledge of STIs, child marriages, ${ }^{14}{ }^{15}$ unsafe sexual practices, ${ }^{16}$ and the lack of access to diagnosis of and treatment facilities for STIs. ${ }^{17} 18$ This inability to address basic human needs may prompt transactional sex and rapid increases in the number of people with STIs. ${ }^{17}$ It is a great concern that HIV, other STIs and intravenous drug use are already highly prevalent among the people of Myanmar. ${ }^{19} 20$ For instance, in 2018, around 240000 people in Myanmar were living with HIV, and the prevalence was $0.7 \%$ (the prevalence was $<0.1 \%$ in Bangladesh). ${ }^{21}$ Also, HIV testing and other basic healthcare services were extremely limited in the Rohingya-predominant northern region of Rakhine State. ${ }^{22}$ Moreover, many Rohingya women were gangraped in Myanmar before they fled to Bangladesh. ${ }^{7}$ Clearly, these factors, together with the current circumstances of the Rohingya refugees, make them vulnerable to HIV and other infectious diseases and may spearhead community transmission in the areas where they live in Bangladesh.

In 2017, soon after these Rohingya people had arrived in Bangladesh, the health authorities carried out diagnostic tests and identified 85 cases of HIV. The cumulative number has risen steadily since then, 273 in August 2018, 319 in March 2019 and 395 in the recent estimate in $2020{ }^{24}$ However, this number is unlikely to represent the true prevalence, as many cases remain undiagnosed and asymptomatic and there are several risk factors for HIV infection and a lack of access to prevention and educational services. In such circumstances, accurate knowledge about HIV transmission and its prevention is crucial to avoiding infection. This is particularly important for people who are at risk, such as women of reproductive age. However, despite the growing risk of HIV infection, data remain scarce regarding the level of knowledge of HIV transmission among Rohingya refugees in Bangladesh. Although a previous survey that examined the knowledge of HIV included both men and women, an estimate for sexually active married women is not available. ${ }^{25}$ Also, in that survey, questions encompassing misconception, such as that HIV is transmitted through mosquito bites, were unavailable, which made the survey data inappropriate for comparison with knowledge level regarding HIV among the people of Myanmar and Bangladesh. ${ }^{25}$ A clear picture of the knowledge these people have about HIV is crucial for developing programmes to build awareness of HIV and provide guidance for those who work in healthcare and social organisations in Rohingya camps. This study aimed to examine the level of knowledge of HIV transmission among Rohingya women living in these camps in Bangladesh and to compare this with the knowledge among women in Myanmar and Bangladesh.

\section{METHODS}

\section{Study setting and design}

A survey was conducted in November 2019 in the Kutupalong refugee makeshift, the largest refugee camp in the world. Geographically, this makeshift is spread in 12949940.552 square meter areas and divided into 34 camps and 208 blocks; each block has an average of 892 households. Around 600000 Rohingya refugees reside there. They are similar in terms of socioeconomic features and usually have equal access to healthcare facilities. We first selected four camps (camp 2E, camp 2W, camp 10 and camp 12) randomly from the list of 34 camps. There were 19 blocks in these four camps, from which eight blocks (two blocks from each camp) were selected randomly for this study. All women who had been married or given birth in the 2 years before the survey were invited to attend face-to-face interviews. These criteria were used to identify all women who were sexually active and had been married after migrating from Myanmar in 2017.

We also compared the knowledge that these Rohingya women had regarding HIV transmission with that of women in Bangladesh and Myanmar, using the 2014 and 2015-2016 waves of the Demographic and Health Survey. The participants in our survey were married and under 42 years of age. We used these two criteria to select a subsample from each Demographic and Health Survey for Bangladesh and Myanmar. The sampling procedure of the Demographic and Health Survey programme has been published elsewhere. ${ }^{26} 27$

\section{Data collection}

Data were collected from 508 Rohingya women using a structured questionnaire. An initial version of the questionnaire was developed by incorporating relevant questions from the Demographic and Health Survey, ${ }^{26}{ }^{27}$ which are validated and recognised worldwide. The questionnaire we developed was first piloted in the field through a survey of 15 Rohingya women, who were selected conveniently from the camps with the same inclusion criteria of the study. Inconsistencies and/or unclarities were noted and then addressed in the final version of the questionnaire. Six local female interviewers, who are fluent in Rohingya dialect and worked in several international organisations as data collectors involving Rohingya people, conducted the interviews. The interviewers all had completed university degrees and lived in communities near Rohingya 
Table 1 Respondents' characteristics and HIV transmission knowledge

\begin{tabular}{|c|c|c|}
\hline Characteristics & $\mathbf{n}$ & Mean (SD) $/ \%$ \\
\hline Women's age & 508 & $23.35( \pm 5.19)$ \\
\hline Women's partner age & 507 & $28.66( \pm 7.95)$ \\
\hline \multicolumn{3}{|l|}{ Women's educational status } \\
\hline Received no education & 119 & 23.43 \\
\hline Received madrasah education* & 258 & 50.79 \\
\hline \multicolumn{3}{|l|}{ Women's work engagement outside household } \\
\hline Only household work & 383 & 75.39 \\
\hline Engaged additional work with household work & 125 & 24.61 \\
\hline \multicolumn{3}{|l|}{ Partner's education } \\
\hline Received madrasah education* & 68 & 13.39 \\
\hline \multicolumn{3}{|l|}{ Partner's working status } \\
\hline Unemployed & 92 & 18.11 \\
\hline Day labourer & 236 & 46.46 \\
\hline Other jobs† & 180 & 35.43 \\
\hline \multicolumn{3}{|l|}{ Women's knowledge of HIV transmission } \\
\hline Relatively good knowledge $\ddagger$ & 153 & 30.12 \\
\hline Relatively poor knowledge§ & 355 & 69.88 \\
\hline
\end{tabular}

*Had gone to mosque/relevant institutions mainly for religious education. †Included all forms of voluntary jobs and services.

$\ddagger$ Accurately answered at least four of the nine questions.

$\S$ Accurately answered fewer than four of the nine questions.

camps. The research team trained the interviewers and supervised the data collection. The questionnaire was in Bengali (the native language of Bangladesh) and read out in Rohingya language while administered. All participants were informed of the purpose of the study and that their participation was voluntary and use of data would be anonymous. Verbal consent was obtained prior to administering the interviews. Verbal rather than written consent was requested due to respondents' low literacy levels and discomfort in providing signatures. Privacy of the selected respondents was ensured by having one-on-one interviews either in participants' houses or outside, without the presence of others.

\section{Patient and public involvement}

No patients were involved.

\section{Outcome variable}

The participants were asked a set of 11 questions to assess their knowledge regarding HIV transmission. These questions were adopted from the Demographic and Health Survey programme. The response options were yes, no and do not know. Participants' responses to 8 of the 11 questions were then used to classify women in terms of whether they had relatively good knowledge or poor knowledge of HIV transmission. Those who answered at least four of the eight questions correctly were identified as having relatively good knowledge and those who answered fewer than four questions accurately were identified as having relatively poor knowledge. Three questions about whether the virus that causes HIV/AIDS can be transmitted from a mother to her baby during (1) pregnancy, (2) delivery and (3) breast feeding had a substantial number of missing responses, and we therefore decided not to include these questions when classifying participants as having good or poor knowledge. A substantial number of missing values would also make the regression imprecise.

\section{Explanatory variables}

We included several independent variables that may be associated with knowledge about HIV transmission. The variables are age, education (received no education, some formal education, madrasah education), marital status (married, divorced/separated/widowed), age at first marriage and work engagement outside households (only household work, engaged in additional work apart from household work). Husbands' age, education (received no education, some formal education, 
Can people get HIV from mosquito bites?

Can people reduce their chance of getting HIV by using a condom every time they have sex?

Can people get HIV by sharing food with a person who has HIV?

Can people get HIV because of witchcraft or other supernatural means?

Can people get HIV by using unsterilised needles or syringes?

Can people reduce their chance of getting HIV by having just one uninfected sex partner who has no other sex partners?

Can a healthy-looking person have HIV?

Can people get HIV through unsafe blood transfusion?

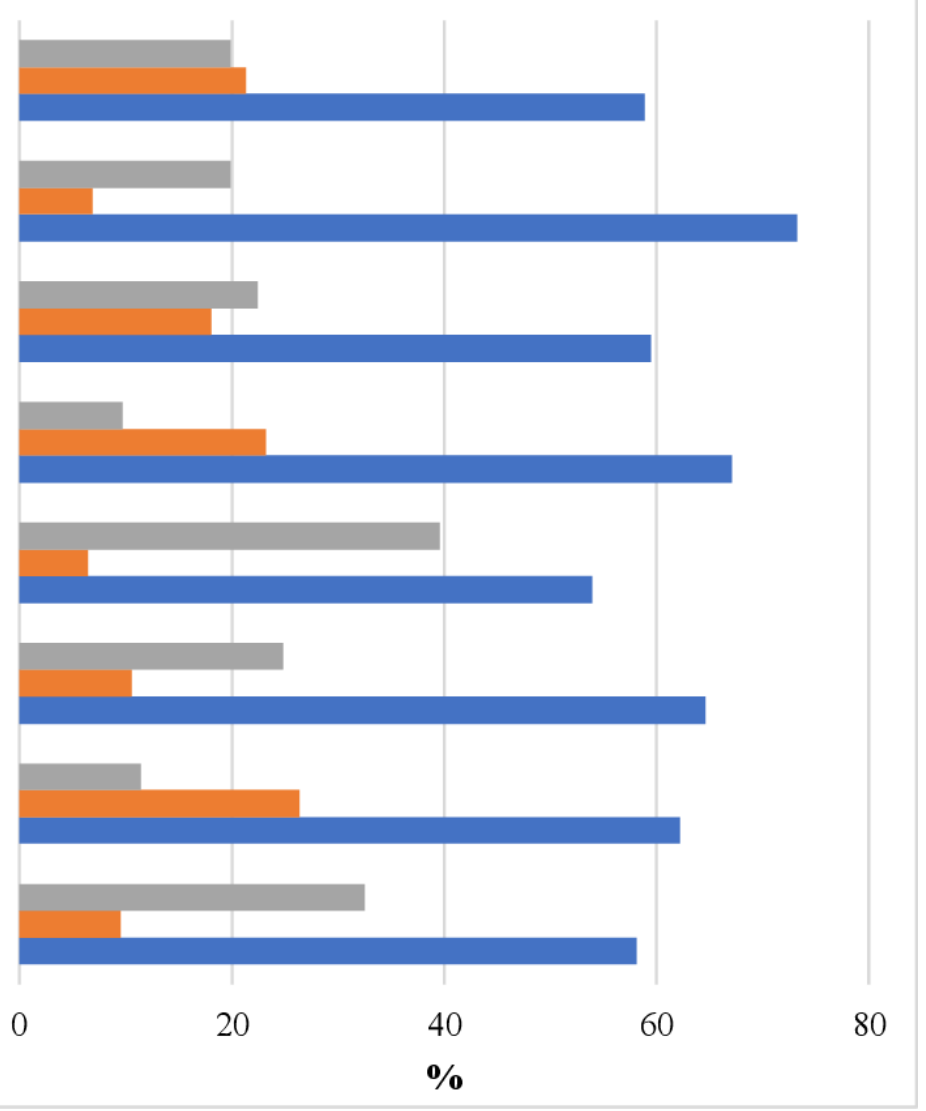

Figure 1 Knowledge of HIV transmission among Rohingya refugee women living in Kutupalong refugee camp in Ukhiya, Cox's Bazar, Bangladesh.

madrasah education) and working status (unemployed, day labourer, other jobs) were the partner-level variables. It should be mentioned that the Rohingya people are not permitted to go outside of camps. Several organisations run some development projects (eg, road construction, water and sanitation) inside the camps through which the Rohingya people can work. Availability of health facilities in blocks where the participants reside (classified as no healthcare services, visits by field workers and mobile healthcare services) was another explanatory variable.

\section{Statistical analysis}

We present the sociodemographic characteristics of women, with mean and SE for continuous variables and with frequencies and percentages for continuous and categorical variables. Knowledge of HIV transmission among women is presented using proportions. Relevant data from the 2014 and 2015-2016 rounds of the Demographic and Health Survey programme for Bangladesh and Myanmar were used to estimate the knowledge of HIV transmission among the women of these two countries and then compared with the knowledge among the Rohingya women. To examine bivariable associations, we used Pearson's $\chi^{2}$ test when both variables were categorical and the t-test when one of the two variables was continuous. A multivariable logistic regression model was used to identify factors associated with level of knowledge of HIV transmission. We also used pairwise proportion tests to compare the proportions of Rohingya, Bangladeshi and Myanmar women who answered the questions about knowledge of HIV transmission correctly. Results were presented as adjusted OR (AOR) along with 95\% CI. All analyses were performed using Stata V.15.1 software.

\section{RESULTS}

Table 1 shows the sociodemographic characteristics of the 508 women who were included in this study. The mean age of the participants was 23.35 years. On average, the women had given birth to three children. About half of the women had received madrasah education, and at the time of the survey three-quarters were doing only household work. Around $30 \%$ of the women had relatively good knowledge of modes of HIV transmission and $70 \%$ had relatively poor knowledge.

Figure 1 shows women's knowledge of HIV transmission. Of the women, $58 \%-73 \%$ responded with the 'don't know' answer option when questions regarding their knowledge of HIV transmission were asked. Incorrect answers varied from $6.5 \%$ to $26 \%$ across these questions. Of the women who identified one or more correct modes of transmission $(11 \%-40 \%$, depending on the 
Table 2 Women's knowledge of HIV transmission across demographic characteristics

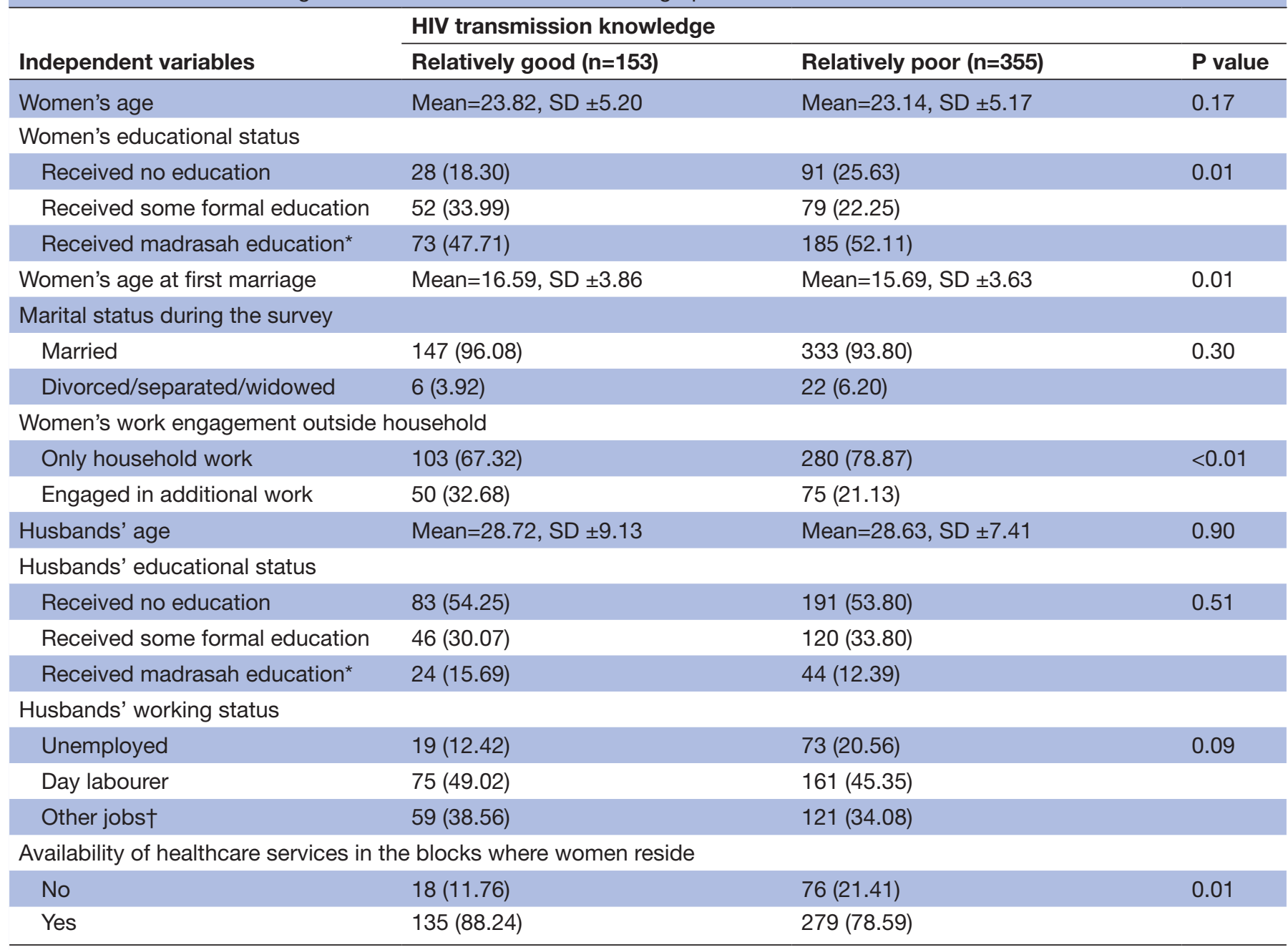

*Had gone to mosque/relevant institutions mainly for religious education.

†Included all forms of voluntary jobs and services.

questions), more women accurately identified the risk of HIV transmission through sharing contaminated syringes than other types of risks.

Table 2 presents the bivariable associations between women's knowledge regarding HIV transmission and the independent variables. Significant variation in knowledge of HIV transmission was found across several variables, namely women's educational status, age at first marriage, work engagement outside their households and availability of healthcare facilities in the blocks where they resided. Women who demonstrated relatively good knowledge were more likely to have received some education from formal educational institutions than women with relatively poor knowledge. The statistical significance of other variables is also shown in table 2 .

Table 3 presents the results of the multivariable associations between the explanatory factors and the level of knowledge about HIV transmission. The knowledge women had regarding HIV transmission increases with age at which they were first married (AOR, 1.09; 95\% CI 1.01 to 1.19$)$. Women who had received formal education were found to be 2.37 times (95\% CI 1.28 to 4.41$)$ more likely to demonstrate a relatively good knowledge of HIV transmission than those who did not receive any education. Also, women who were engaged in additional work outside their households (AOR, 1.76; 95\% CI 1.06 to 2.91) and whose husbands were employed were more likely to demonstrate relatively good knowledge. The availability of healthcare services in the blocks where the women resided was associated with relatively good knowledge as well (AOR, 2.13; 95\% CI 1.16 to 3.89 ).

Table 4 provides a comparison between the Rohingya, Bangladeshi and Myanmar women in terms of percentages of correct responses they gave to questions about knowledge of HIV transmission. Rohingya women demonstrated substantially lower levels of knowledge about HIV transmission in their answers to all eight questions than did the Myanmar and Bangladeshi women. These differences were around 50 percentage points for most questions about their knowledge of HIV transmission. 
Table 3 Multivariable logistic regression model assessing the factors associated with knowledge of HIV transmission among Rohingya refugee women $(n=489)$

\begin{tabular}{|c|c|c|}
\hline \multirow[b]{2}{*}{ Independent variables } & \multicolumn{2}{|c|}{ Good knowledge of HIV/AIDS } \\
\hline & OR & $P$ value \\
\hline Women's age & $1.06(0.99-1.14)$ & 0.08 \\
\hline \multicolumn{3}{|l|}{ Women's educational status } \\
\hline Received no education (ref) & 1.00 & \\
\hline Received some formal education & $2.37(1.28-4.41)$ & $<0.01$ \\
\hline Received madrasah education* & $1.60(0.90-2.85)$ & 0.11 \\
\hline Women's age at first marriage & $1.09(1.01-1.19)$ & 0.04 \\
\hline \multicolumn{3}{|l|}{ Marital status during the survey } \\
\hline Divorced/separated/widowed (ref) & 1.00 & \\
\hline Married & $1.75(0.61-5.03)$ & 0.30 \\
\hline \multicolumn{3}{|c|}{ Women's work engagement outside household } \\
\hline Only household work (ref) & 1.00 & \\
\hline Engaged in additional work & $1.76(1.06-2.91)$ & 0.03 \\
\hline Husbands' age & $0.97(0.93-1.01)$ & 0.13 \\
\hline \multicolumn{3}{|l|}{ Husbands' educational status } \\
\hline Received no education (ref) & 1.00 & \\
\hline Received some formal education & $0.67(0.42-1.07)$ & 0.09 \\
\hline Received madrasah education* & $1.16(0.63-2.13)$ & 0.64 \\
\hline \multicolumn{3}{|l|}{ Husbands' working status } \\
\hline Unemployed (ref) & 1.00 & \\
\hline Day labourer & $1.97(1.05-3.70)$ & 0.03 \\
\hline Other jobst & $1.96(1.02-3.79)$ & 0.04 \\
\hline \multicolumn{3}{|c|}{ Availability of healthcare services in the blocks where women reside } \\
\hline No & 1.00 & \\
\hline Yes & $2.13(1.16-3.89)$ & 0.01 \\
\hline Constant & $0.006(0.001-0.05)$ & $<0.01$ \\
\hline
\end{tabular}

Values marked in bold indicate statistically significant results.

*Had gone to mosque/relevant institutions mainly for religious education. †Included all forms of voluntary jobs and services.

Ref, Reference category.

\section{DISCUSSION}

This study examined the awareness of Rohingya refugee women with regard to HIV transmission. Overall, the study suggests that the participants had noticeably lower level of knowledge about HIV than the women in Bangladesh and Myanmar. Our results suggest that women's age at first marriage, their educational status, whether they worked outside their households, whether their husbands were employed and availability of healthcare services in the blocks where they reside were significantly associated with level of knowledge. Given the relatively high prevalence of HIV among the Rohingya people and the fact that many are likely to be undetected, the findings of this study highlight the importance of offering health education and promoting interventions to reduce the risk of spreading this infection among the Rohingya people and host communities.
Although HIV prevention is acknowledged as an important public health concern in refugee settings, ${ }^{28} 29$ the demand to address immediate needs such as food, shelter and sanitation may put prevention efforts lower on the priority list. ${ }^{30}$ However, the increasing trend in terms of the prevalence of HIV and the substantial risk factors should not be taken lightly. The Rohingya refugees who have most recently fled from Myanmar are mainly women and children, and over $23 \%$ of the women are widowed. ${ }^{131}$ This gender imbalance may break down family and social ties and traditional values, promote sexual activity among children at younger ages, ${ }^{32}$ and increase polygamy, sex outside marriage, sexual coercion, abuse and rape. ${ }^{32-34}$ There is information indicating that to satisfy the unmet needs of their day-to-day lives some Rohingya women are involved in illicit drug trade and prostitution, ${ }^{35}$ and that the people of the Bangladesh 
host community are the main customers. ${ }^{36}$ All of these risk behaviours and underlying factors can accelerate HIV transmission unless education about HIV and basic preventive measures are taken.

The age of women when they were first married and their educational status were significant determinants of their knowledge about HIV. These observations may be useful in programming appropriate HIV prevention strategies. For instance, women of relatively young ages who had received no formal education could be targeted in raising awareness of HIV prevention. The government of Bangladesh has now granted permission to Rohingya girls and boys to have formal schooling, ${ }^{37}$ and this opens the door to being able to inform children and adolescents about HIV transmission and prevention.

The reduced mobility of the Rohingya refugees, since their camps are located in a relatively isolated area, ${ }^{38}$ and their religious restrictions regarding sexuality may in fact work as protective factors. However, several factors including cultural and religious sensitivity may work negatively, and they must be considered when designing interventions to improve HIV awareness. For example, programmes for safer sex that promote the use of condoms may not be effective because the religious customs of the Rohingya people are not compatible with condom use and family planning services. ${ }^{39}$ In addition, since their religious customs do not permit sexual engagement outside marriage, should these activities exist, they generally remain hidden. Religious customs such as these may also limit movement among Rohingya women, including their access to reproductive healthcare services. The inclusion of husbands in interventions to raise awareness might be useful as well. ${ }^{40}$

Our study found a positive association between availability of healthcare facilities in the blocks where women resided and a relatively good knowledge about HIV transmission. Further research is needed to examine to what extent this association is attributed to the services offered by the healthcare facilities in the blocks. In addition to providing basic primary healthcare services, these facilities can play a pivotal role in the diagnoses of new HIV cases and in improving knowledge of HIV prevention and linking HIV patients to tertiary healthcare facilities. ${ }^{41}$ Evidence is also available to suggest that Rohingya people who live in the camps and are HIV-positive are given antiretroviral treatment, ${ }^{42}$ although how they are managed in terms of their health and social care is unknown.

This study has some limitations. First, we did not interview unmarried girls and women. Some of these girls and women might be at increased risk of HIV transmission, particularly if they experience sexual violence ${ }^{43}$ and/ or are involved in transactional sex. ${ }^{44}$ Also, we did not validate participants' knowledge of HIV transmission or examine HIV-related behaviours. Moreover, only a limited set of variables were available for the multivariable regression and the underlying reasons why the participants had inadequate knowledge of HIV transmission 
were not explored. In addition, the use of cross-sectional data means that we cannot infer causality. Given that the refugee situation is context-specific, ${ }^{45}{ }^{46}$ further study is needed with regard to Rohingya refugees living outside camps in Bangladesh.

\section{CONCLUSIONS}

This study suggests that a high proportion of women who live in the Rohingya refugee camps lack adequate knowledge about HIV transmission. Women's age, educational status and availability of healthcare services in the blocks where they resided were positively associated with level of knowledge. Appropriate programmes are needed to increase HIV awareness and coverage of healthcare services in the Rohingya camps.

Correction notice This article has been corrected since it was first published. The funding statement has been corrected.

Acknowledgements We thank La Trobe Asia for all its support.

Contributors NK and MMI designed the study. NK conducted the analysis. NK and MMI wrote the manuscript. MMI, MMoR and MMaR critically reviewed the manuscript. MMaR supervised the data collection. All authors approved the final version of this manuscript.

Funding The authors received funding from La Trobe Asia for this research.

Competing interests None declared.

Patient and public involvement Patients and/or the public were not involved in the design, or conduct, or reporting, or dissemination plans of this research.

\section{Patient consent for publication Obtained.}

Ethics approval The Ethical Board of the Institute of Biological Sciences of Rajshahi University in Bangladesh reviewed and provided ethical approval for this study with approval number 123/320/IAMEBBC/IBSC.

Provenance and peer review Not commissioned; externally peer reviewed.

Data availability statement Data are available upon reasonable request. We confirmed that the data supporting the findings of this study are fully available within the manuscript. Derived data are not publicly available. However, data are available from the corresponding author on reasonable request.

Open access This is an open access article distributed in accordance with the Creative Commons Attribution Non Commercial (CC BY-NC 4.0) license, which permits others to distribute, remix, adapt, build upon this work non-commercially, and license their derivative works on different terms, provided the original work is properly cited, appropriate credit is given, any changes made indicated, and the use is non-commercial. See: http://creativecommons.org/licenses/by-nc/4.0/.

\section{ORCID iDs}

Md Nuruzzaman Khan http://orcid.org/0000-0002-4550-4363

M Mofizul Islam http://orcid.org/0000-0003-1330-863X

\section{REFERENCES}

1 Habib M, Jubb C, Ahmad S. Forced migration of rohingya: an untold experience. Available at SSRN 32426962018.

2 Abdelkader E. The history of the persecution of Myanmar's Rohingya. The Conversation, 2017. Available: https://theconversation.com/thehistory-of-the-persecution-of-myanmars-rohingya-84040

3 Human Rights Watch. Burmese refugees in Bangladesh: still no durable solution, 2000. Available: https://www.hrw.org/report/2000/ 05/01/burmese-refugees-bangladesh/still-no-durable-solution\#

4 Fox News. Bangladesh point finger at Myanmar for Rohingya 'genocide', 2018. Available: https://www.foxnews.com/world/ bangladesh-point-finger-at-myanmar-for-rohingya-genocide

5 Human Rights Watch. Crimes against humanity by Burmese security forces against the Rohingya Muslim population in northern Rakhine state since August 25, 2017. human rights watch, Sept 25, 2017, 2020. Available: https://www.hrw.org/news/2017/09/25/crimes- against-humanity-burmese-security-forces-against-rohingya-muslimpopulation

6 Parmar PK, Leigh J, Venters $\mathrm{H}$, et al. Violence and mortality in the Northern Rakhine state of Myanmar, 2017: results of a quantitative survey of surviving community leaders in Bangladesh. Lancet Planet Health 2019;3:e144-53.

7 Wikipedia. Rohingya genocide, 2020. Available: https://en.wikipedia. org/wiki/Rohingya_genocide

8 MSF. Msf surveys estimate that at least 6,700 Rohingya were killed during the attacks in Myanmar, December 142017 https://www.msf. org/myanmarbangladesh-msf-surveys-estimate-least-6700-rohingyawere-killed-during-attacks-myanmar

9 Department of State USA. Documentation of atrocities in northern Rakhine state. Washington DC, USA, 2018. Available: https://www. state.gov/wp-content/uploads/2019/01/Documentation-of-Atrocitiesin-Northern-Rakhine-State.pdf

10 The Lancet. The Rohingya people: past, present, and future. The Lancet 2019;394:2202.

11 United Nations High Commissioner for Refugees. Operational update: Bangladesh (27 December 2017-7 January 2018. Bangladesh: UNHCR, 2017. https://data2.unhcr.org/en/documents/ download/61561

12 Pocock NS, Mahmood SS, Zimmerman C, et al. Imminent health crises among the Rohingya people of Myanmar. BMJ:j5210.

13 Tanabe M, Greer A, Leigh J, et al. An exploration of genderbased violence in eastern Myanmar in the context of political transition: findings from a qualitative sexual and reproductive health assessment. Sex Reprod Health Matters 2019;27:112-25.

14 Islam MM, Khan MN, Rahman MM. Factors affecting child marriage and contraceptive use among Rohingya girls in refugee camps. Lancet Reg Health West Pac 2021;12:100175.

15 Islam MM, Khan MN, Rahman MM. Attitudes to and experiences of intimate partner violence among Rohingya women who married before eighteen years of age. Glob Health Action 2021;14:1943852.

16 Khan MN, Islam MM, Rahman MM, et al. Access to female contraceptives by Rohingya refugees, Bangladesh. Bull World Health Organ 2021;99:201-8.

17 UN. UN warns of trafficking, sexual abuse in shadow of Rohingya refugee crisis. UN News, 2017. Available: https://news.un.org/en/ story/2017/11/636002-un-warns-trafficking-sexual-abuse-shadowrohingya-refugee-crisis

18 Ivanova O, Rai M, Kemigisha E. A systematic review of sexual and reproductive health knowledge, experiences and access to services among refugee, migrant and displaced girls and young women in Africa. Int J Environ Res Public Health 2018;15:1583.

19 UN. UNAIDSWHO Working group on global HIV/AIDS and STI surveillance Myanmar: HIV/AIDS updates, 2004. Available: http:// data.unaids.org/publications/fact-sheets01/myanmar_en.pdf

20 Hossain MM, Sultana A, Mazumder $\mathrm{H}$, et al. Sexually transmitted infections among Rohingya refugees in Bangladesh. Lancet HIV 2018;5:e342.

21 Global information and education on HIV and AIDS. HIV and AIDS in Myanmar, 2018. Available: https://www.avert.org/professionals/hivaround-world/asia-pacific/myanmar\#footnote1_xqektc2

22 Mahmood SS, Wroe E, Fuller A, et al. The Rohingya people of Myanmar: health, human rights, and identity. Lancet 2017;389:1841-50

23 UNICEF. Rakhine state profile. Myanmar, 2015. Available: https:// www.unicef.org/myanmar/rakhine-state

24 Ukhiya News. 319 Rohingyas affected by AIDS, 2019. Available: http://en.ukhiyanews.com/by-aids

25 Innovations for Poverty Action UNICEF. Current level of knowledge, attitudes, practices, and behaviours (KAPB) of the rohingya refugees and host community in cox's bazar: a report on findings from the baseline survey. Banani, Dhaka: Innovations for Poverty Action, UNICEF, 2018.

26 National Institute of Population Research and Training (NIPORT) MaA, and ICF International. Demographic and health survey 2014. Bangladesh Dhaka, Bangladesh, and Rockville, Maryland, USA: NIPORT, Mitra and Associates, and ICF International, 2016.

27 Ministry of Health and Sports (MoHS) and ICF. Myanmar demographic and health survey 2015-16. Nay Pyi Taw, Myanmar and Rockville, Maryland USA: Ministry of Health and Sports and ICF, 2017.

28 WHO. Bangladesh: Rohingya refugee crisis 2017-2018 2019.

29 Reliefweb. Emergency: Rohingya crisis - WHO Bangladesh situation report \#32, 17 November 2020 (Period covered: Week 46: 9 November - 15 November) 2020.

30 Refweb. Delivering antiretroviral drugs in emergencies: neglected but feasible 2006. 
31 XCHANGE. The Rohingya survey 2019, 2019. Available: https://www. humanitarianresponse.info/en/operations/bangladesh/assessment/ xchange-rohingya-survey

32 UNAIDS. Refugees and AIDS: UNAIDS point of view joint United nations programme on HIV and AIDS, Geneva, Swezarland, 1997. Available: https://www.unaids.org/sites/default/files/media_asset/ MDG6Report_en.pdf

33 Woodward A, Howard N, Kollie S, et al. Hiv knowledge, risk perception and avoidant behaviour change among Sierra Leonean refugees in guinea. Int J STD AIDS 2014;25:817-26.

34 Dahab M, Spiegel PB, Njogu PM, et al. Changes in HIV-related behaviours, knowledge and testing among refugees and surrounding national populations: a multicountry study. AIDS Care 2013;25:998-1009.

35 Center MP. Socio-Political impacts of Rohingya refugees on Bangladesh. MPC Report Series 2018.

36 Observer Research Foundation. Drug trafficking and Rohingya refugees in Bangladesh. Observer Research Foundation, 2019. Available: https://www.orfonline.org/expert-speak/drug-traffickingand-rohingya-refugees-in-bangladesh-49005/

37 Ahmed K. Bangladesh grants Rohingya refugee children access to education. The Guardian 2020.

38 Spiegel PB. Hiv/Aids among conflict-affected and displaced populations: dispelling myths and taking action. Disasters 2004;28:322-39.
39 NDTV. Bangladesh eyes sterilisation to curb Rohingya population. India: NDTV, 2019. https://www.ndtv.com/world-news/bangladesheyes-sterilisation-to-curb-rohingya-population-1768155

40 UNHCR. Refugees and HIV, 2020. Available: https://www.unhcr.org/ en-au/protection/health/45e58abc2/refugees-hiv-plusnews.html

41 WHO. World Health Organization Humanitarian Response Plans 2016. The World Health Organization, Geneva, Swezarland, 2016. Available: https://www.who.int/hac/donorinfo/who_humanitarian_ response_plan_2016_may.pdf

42 Refworld. At least 62 Rohingya refugees have HIV/AIDS, Bangladesh officials say, 2017. Available: https://www.refworld.org/docid/ $5 \mathrm{a} 9427 \mathrm{dc} 6 . \mathrm{htm}$

43 Islam MM, Khan MN, Rahman MM. Intimate partner abuse among Rohingya women and its relationship with their abilities to reject husbands' advances to unwanted sex. J Interpers Violence 2021;886 260521991299:886260521991299.

44 Glinski S. Clandestine sex industry Booms in Rohingya refugee camps. London, UK: Global Citizen, 2017. https://www.globalcitizen. org/en/content/sex-industry-in-rohingya-refugee-camps/?template= next

45 Tanaka Y, Kunii O, Hatano T, et al. Knowledge, attitude, and practice (KAP) of HIV prevention and HIV infection risks among Congolese refugees in Tanzania. Health Place 2008;14:434-52.

46 Hankins CA, Friedman SR, Zafar T, et al. Transmission and prevention of HIV and sexually transmitted infections in war settings: implications for current and future armed conflicts. AIDS 2002;16:2245-52. 